\title{
Educação e mercado financeiro: um estudo sobre a Anhanguera, Estácio e Kroton (2007-2014)
}

\author{
Education and financial market: a study on Anhanguera, Estácio and \\ Kroton (2007-2014)
}

\author{
Educación y mercado financiero: un estudio sobre Anhanguera, \\ Estácio y Kroton (2007-2014) \\ Fábio Luciano Oliveira Costa ${ }^{1}$ \\ Universidade Estadual de Mato Grosso do Sul, Professor. \\ http://orcid.org/0000-0002-8944-207X
}

Resumo: 0 objetivo principal deste texto buscou discutir a financeirização do capital no ensino superior com fins lucrativos no Brasil, de 2007 a 2014. Os três estudos de caso, da Anhanguera, Estácio e Kroton, inserem-se num processo mais amplo de financeirização mundial do capital, nos últimos 50 anos. Para viabilizar o trabalho, realizou-se uma análise qualitativa, por meio de pesquisa bibliográfica, pesquisa documental e estudos de caso. Pela análise dos dados operacionais e financeiros foi possível perceber o importante crescimento para todas elas. Por meio de parcerias importantes, tais quais aquelas realizadas com os Fundos de Equidade Privada, o Fundo Público, as fusões e aquisições, seu público consumidor, junto com o sucesso na gestão corporativa das companhias, ocorreu a quase constante valorização acionária na bolsa de valores, num breve espaço de tempo.

Palavras-chave: Educação. Financeirização do Capital. Anhanguera. Estácio. Kroton.

Abstract: The main objective of this text sought to discuss the financialization of capital in higher education for profit in Brazil, from 2007 to 2014. The three case studies, by Anhanguera, Estácio and Kroton, are part of a broader process of global financialization of capital, in the last 50 years. To make the work feasible, a qualitative analysis was carried out, through bibliographic research, documentary research and case studies. By analyzing the operational and financial data, it was possible to see the important growth for all of them. Through important partnerships, such as those carried out with the Private Equity Funds, the Public Fund, mergers and acquisitions, its consuming public, together with the success in the corporate management of the companies, there was an almost constant share appreciation on the stock exchange, in a short space of time.

Keywords: Education. Financialization of Capital. Anhanguera. Estácio. Kroton. 
Resumen: El objetivo principal de este texto buscó discutir la financiarización del capital en la educación superior con fines de lucro en Brasil, de 2007 a 2014. Los tres estudios de caso, de Anhanguera, Estácio y Kroton, son parte de un proceso más amplio de financiarización global del capital, en los últimos 50 años. Para viabilizar el trabajo, se realizó un análisis cualitativo, a través de la investigación bibliográfica, la investigación documental y los estudios de casos. Al analizar los datos operativos y financieros, fue posible ver el importante crecimiento de todos ellos. A través de importantes alianzas, como las realizadas con los Fondos de Capital Privado, el Fondo Público, las fusiones y adquisiciones, su público consumidor, unido al éxito en la gestión corporativa de las empresas, se produjo una revalorización casi constante de las acciones en bolsa, en un corto espacio de tiempo.

Palabras-clave: Educación. Financialización del capital. Anhanguera. Estácio. Kroton.

Recebido em 15 de março de 2020

Aceito em 13 de julho de 2020

Publicado em 24 de setembro de 2020

\section{INTRODUÇÃO}

0 objetivo principal deste trabalho consiste na investigação sobre o estreitamento dos laços entre a Educação e o Capital Financeiro, no Brasil, no período de 2007 a 2014. Para viabilizar o objetivo principal foram selecionados três estudos de caso, da Anhanguera Educacional S.A, Estácio Participações S.A, e Kroton Educacional S.A.2 Por meio dessas empresas educacionais, ou companhias, buscou-se determinar quais os novos elementos caracterizam esse processo na área da educação, mas que tem tradição maior em outros setores da indústria nacional e internacional.

A financeirização do capital na educação brasileira apareceu inicialmente, de forma mais evidente, no ensino superior com finalidades lucrativas (particular), quando a essas Instituições de Ensino Superior (IES) foi confiada a forte expansão no número de matrículas para esse nível de ensino, sobretudo desde o final do século XX e início do XXI.

Dentro desse processo, uma de suas características mais importantes trata da constituição de conglomerados industriais, ou as chamadas holdings educacionais, ou seja, de uma empresa que administra várias outras empresas. Uma série de novos parceiros se agregaram às companhias, e o artigo assume a preocupação em mostrar esses agentes, públicos e privados, envolvidos com a financeirização do capital no ensino superior particular.

2 De agora em diante, apenas Anhanguera, Estácio e Kroton. 
Pelo seu caráter recente, o tema cria a necessidade de mais trabalhos que se debrucem sobre a questão. Este texto pretende contribuir para reduzir essa lacuna. Nesse sentido, privilegiou-se a análise qualitativa sobre o objeto de pesquisa, por meio de pesquisa bibliográfica (seleção de livros, teses acadêmicas, artigos científicos publicados em períodos diversos associados ao tema), pesquisa documental (a legislação pertinente à discussão), e estudos de caso (com informações operacionais e financeiras disponibilizadas no site da relação de investidores de cada uma das 3 companhias, no período de 2007 a 2014).

Além desta introdução, o texto conta com mais 3 partes. Na primeira, abordam-se questões associadas à financeirização do capital no ensino superior particular no Brasil. Em seguida, tratam-se das 3 companhias selecionadas, ou seja, da Anhanguera, Estácio e Kroton. Por fim, as considerações finais rapidamente retornam aos principais resultados da pesquisa.

\section{A FINANCEIRIZAÇÃO DO CAPITAL NO ENSINO SUPERIOR PARTICULAR BRASILEIRO}

A atual fase de expansão financeira, em nível mundial, teve início no final dos anos de 1960 e 1970, com o aparecimento de novos instrumentos financeiros, principalmente nas maiores economias industriais, a exemplo dos Estados Unidos, dos países da Europa Ocidental e do Japão.

Esses países assumiram o discurso da necessidade de crescimento para a liberalização e desregulamentação econômica (mediante as diversas formas de protecionismo interno), o que tem permitido um maior volume não só das transações comerciais, mas sobretudo das financeiras, entre as distintas nações do planeta. Com a desregulamentação dos mercados de capitais apareceram uma série de instrumentos de derivativos, securitização, contratos futuros, entre outros; de instituições financeiras; de grupos financeiros; que com os recursos das tecnologias da informação e comunicação movimentam elevadas somas de capitais, todos os dias.

Para a área da educação, em especial no ensino superior, os Estados Unidos também se constituíram como pioneiros no processo de financeirização do capital, ao apresentar as primeiras Instituições de Ensino Superior (IES) a abrir o capital e a comercializar suas ações na bolsa de valores (CARVALHO, 2012; COSTA, 2016).

A primeira empresa educacional a abrir o seu capital, conhecida como Initial Public Offering (IPO), ou Oferta Pública de Ações (OPA), numa bolsa de valores ${ }^{3}$ foi a Devry Education

Além dos Estados Unidos e do Brasil, paises como a África do Sul, Índia e o Reino Unido também possuem empresas educacionais comercializando as suas ações em bolsas de valores (BALL, 2004). 
Group, Inc., em 1991, na National Association of Securities Dealers Automated Quotations (NASDAQ). Essa abertura geralmente permite a capitalização de importantes somas de recursos financeiros, que muitas vezes são gastos nos processos de aquisições e fusões ${ }^{4}$ com outras empresas, ou na reestruturação e abertura de novas unidades para a expansão do negócio.

No ano de 1995, as ações da Devry começaram a ser negociadas na New York Stock Exchange (NYSE) - Bolsa de Valores de Nova York -, e no ano seguinte, na Chicago Stock Exchange (Bolsa de Chicago). Também se pode citar outras empresas educacionais, a exemplo do Apollo Educational Group, Inc., que realizou sua OPA em 1994, na NYSE. Em 2011, esse grupo, que atuava também na Europa, no Chile, México e na Índia teve uma receita líquida de US $\$$ 4,7 bilhões, além de um valor de mercado estimado em US $\$ 2,29$ bilhões (SOUSA, 2012).

No ano acadêmico norte-americano de 2008/2009, aproximadamente 1,8 milhão (9,2\%), de um total de mais de 19,5 milhões de estudantes no ensino superior estavam matriculados em IES do setor privado com fins lucrativos, onde atingiram um crescimento de quase $600,0 \%$, num período de pouco mais de 20 anos. Com relação ao número de IES nesse segmento, chegaram a quase 2.900 (mais de 40,0\%) de um total próximo a 6.700 (BENNETT; LUCCHESI; VEDDER, 2010). Em pesquisa feita no endereço eletrônico ${ }^{5}$ da NASDAQ, no dia 15 de maio de 2014, para o setor schools havia 25 empresas listadas.

Diante da importância nos índices de crescimento de tais empresas no âmbito do ensino superior norte-americano, algumas delas têm atuado em diversos lugares do planeta, inclusive no Brasil. Como no país não há ainda nenhuma restrição quanto à participação do capital estrangeiro nesse nível de ensino, desde o começo dos anos 2000, várias movimentações financeiras, como aquisições e fusões de IES têm sido realizadas no território nacional.

No Projeto de Lei $n^{\circ} 7.200$ (BRASIL, 2006), que ainda tramita no Congresso Nacional, consta que para a manutenção de uma IES com fins lucrativos, pelo menos 70,0\% de seu capital votante associado às mantenedoras tem que pertencer a brasileiros natos ou naturalizados, - que impede também a abertura de franquias que não cumpram as regras.

Em 2001, o grupo Apollo estabeleceu parceria com a Rede Pitágoras para a criação de suas primeiras faculdades, a qual durou até 2005, quando decidiu vender sua participação para os fundadores da empresa que hoje é conhecida como Kroton. A CM Consultoria destacou a ampliação da participação do capital estrangeiro a partir da segunda metade dos anos 2000, quando observaram a fragmentação no ensino superior brasileiro e a possibilidade de boas taxas de retorno financeiro (CMCONSULTORIA, 2014).

\footnotetext{
4 Sobre o tratamento, de forma geral favorável ao tema associado às fusões e aquisições, sugere-se a consulta de Barros (2001) e Camargos e Barbosa (2006).

5 Consultar: http://www.nasdaq.com.
} 
Ainda segundo a empresa de consultoria acima, a Laureate, que em 2014 atuou em 29 países e apresentou um número aproximado de 750 mil estudantes matriculados, foi a empresa educacional estrangeira que mais adquiriu IES no Brasil, de 2007 a 2013, já que esteve envolvida em $१ 2$ transações comerciais. Além dela, empresas educacionais multinacionais como a Whitney International University System, ou o Grupo Pearson, desde meados dos anos 2000, têm realizado aquisições de IES no país.

Essas companhias são submetidas a todas as regras que qualquer IES teoricamente deve respeitar no território nacional. 0 seu campo de atuação não se dá apenas com o ensino presencial, mas também a distância, bem como com a venda de materiais didáticos e de tecnologias, entre outros. Ainda, beneficiam-se de algumas políticas públicas para a área, a exemplo do Fundo de Financiamento Estudantil (FIES) e do Programa Universidade para Todos (PROUNI), constituídos com recursos financeiros do Fundo Público.

Outros atores importantes nesse cenário consistiram nos Private Equity Funds, que compreendem fundos financeiros de capitais que compram participações em empresas, de capital aberto ou fechado, no intuito também de melhorar a gestão corporativa do negócio e elevar suas margens de lucro. Conforme Alonso (2010, p. 1):

\footnotetext{
[..] as empresas que recebem os aportes já estão consolidadas e possuem faturamento na casa das dezenas ou centenas de milhões de reais. 0 objetivo dos recursos é de dar um impulso financeiro à companhia para que ela se prepare para abrir capital na bolsa de valores, por exemplo. Empresas de capital aberto também podem receber os recursos dos private equity. Neste caso, o capital é destinado a alterações financeiras, operacionais ou estratégicas, visando a um novo posicionamento no mercado aberto.
}

Só para citar alguns exemplos, o Cartesian Capital Group havia obtido participação minoritária no grupo Maurício de Nassau, hoje parte da Ser Educacional S.A., em 2009, cujos valores não foram revelados; o Capital International, Inc. investiu R\$ 130,0 milhões no Instituto Brasileiro de Mercado de Capitais (BMMEC) e nas faculdades Veris, no ano de 2010; enquanto o Actis comprou 37,0\% do Grupo Cruzeiro do Sul, por R\$ 180,0 milhões, em 2012 (CMCONSULTORIA, 2014).

Há também Fundo de Equidade Privada nacional investindo no ensino superior do setor privado brasileiro, a exemplo do BR Investimentos, que em 2012 aplicou R $\$$ 100,0 milhões na Anima Educação S.A., ou ainda gestoras de recursos independentes, como no caso da Pollux Capital Administradora, que no mesmo ano acima aumentou sua participação acionária na Estácio para 5,16\%, em relação ao total.

Ainda pelos dados da empresa de consultoria, outros atores internacionais têm tido atuação importante no setor, como a International Finance Corporation (IFC), pertencente 
ao Banco Mundial, que fez um empréstimo para a Laureate, em 2013, no valor de US\$150,0 milhões, além de outros empréstimos para a Anhanguera e Estácio, nos últimos anos.

0 número total de fusões e aquisições no ensino superior do setor privado brasileiro, de 2007 a 2013, chegou a 168 transações. Nessas negociações comerciais foram gastos cerca de $R \$ 10,457$ bilhões (sem correção monetária), o que envolveu mais de 2,1 milhões de matrículas, e o valor médio de $R \$ 7.562,3$ para cada uma delas. Os gastos com as aquisições e fusões no ensino superior do setor privado brasileiro cresceram aproximadamente $752,5 \%$, de 2007 a 2013 . Para as $\mathbb{E}$ ES particulares, no geral, o faturamento aumentou $29,6 \%$, quando passou de $R \$ 24,7$ bilhões, em 2011 , para um valor estimado de $R \$$ 32,0 bilhões, em 2013 (GUILHERME; GLENIA, 2013).

Além da atuação dos Fundos de Equidade Privada, em sua maior parte estrangeiros, nos negócios recentes do mercado de ensino superior no país, de acordo com os dados apresentados pela Hoper, para o ano de 2013, a Debry comprou a FACID, no Piauí, e a Laureate adquiriu a Anhembi Morumbi e a FMU, em São Paulo (SGUISSARDI, 2014). Essas duas universidades de origem norte-americana, no mesmo ano, encontravam-se no grupo das dez maiores companhias de ensino superior privado no Brasil.

Assim, Carvalho (2011), Chaves (2010), Oliveira (2009), e outros, mostraramse preocupados com o processo de oligopolização no setor privado, principalmente pela concentração de matrículas em algumas poucas $\mathbb{E} E S$ particulares, onde geralmente uma mantenedora (holding) controla a movimentação financeira e administrativa de várias mantidas.

As aquisições e fusões são apenas uma das várias estratégias que tem reorganizado a administração das empresas de ensino superior no setor privado não só no Brasil, mas também em alguns outros países, principalmente nos Estados Unidos. Por essa via, soma-se a esses fatores, conforme Hessel e Marrey (2007), ao citarem Ryon Braga, fundador e presidente da Hoper, o fato de que a qualidade (mas qual qualidade?) se tornou um dos quesitos fundamentais para que as $\mathbb{E}$ ES possam ter sucesso na sua administração cotidiana, o que envolve também sua valorização acionária na bolsa de valores, para aquelas que contam com seu capital aberto.

Para melhor discutir essas novas práticas de governança corporativa, usar-seão os estudos de 3 empresas educacionais selecionadas para verificar como tais diretrizes têm estruturado essas IES particulares do setor privado, o que será feito adiante. Assim, veremos como os estudos de caso, a exemplo da Anhanguera, Estácio e Kroton dialogam com essas questões. 


\section{A ANHANGUERA, ESTÁCIO E KROTON (2007-2014)}

No trabalho de Costa (2016), uma das preocupações do autor consistiu na abordagem de mecanismos legais, depois da promulgação da Constituição Federal de 1988 (como Leis, Decretos, Medidas Provisórias, Portarias e Resoluções), que incentivaram o forte crescimento do ensino superior privado com fins lucrativos no Brasil, principalmente nas duas últimas décadas.

Ainda, o autor também dedicou atenção especial às novas estratégias de gestão corporativa e a entrada de determinadas IES privadas com fins lucrativos no mercado de ações da BM\&FBovespa, no país, em 2007, e mais recentemente, nos Estados Unidos; a parceria com grandes fundos de investimentos (nacionais e internacionais); as poucas melhorias na distribuição de renda no país nos últimos anos, com o crescimento no número de trabalhadores que estudam; a fragmentação no setor privado, com grande número de $\mathbb{E}$; a perspectiva de ascensão profissional e aumento salarial; os incentivos estatais, por meio da avaliação e regulação no ensino superior privado, além das bolsas de estudos (públicas e privadas), e da renúncia fiscal que permitiram um forte crescimento para todas elas.

A profissionalização da gestão institucional das grandes empresas na área da educação, que se formaram nos últimos anos, tem sido a questão central para suas administrações. A eficiência, criação de valor, consolidação da marca ou a qualidade, entre outros, constituíram-se como temas que não podem ficar de fora do negócio.

Vários autores, recentemente, têm trabalhado com a questão. No ambiente da produção intelectual escrita, há posições favoráveis e contrárias a essas estratégias de gestão corporativa, que são novas para a área da educação privada com fins lucrativos no Brasil, mas com mais experiência em outros setores no mundo dos negócios.

Por exemplo, Sguissardi (2014, p. 97), ao tratar da mundialização do capital produtivo, sob os termos do economista e professor francês François Chesnais, ${ }^{6}$ fala dos modelos contemporâneos de gestão corporativa, adotados por muitas grandes empresas, em nível mundial, que envolvem os processos de produção e organização do trabalho, para estreitar os laços com o que pode ser chamado de capital improdutivo, no mercado financeiro.

Para o autor, todo o processo estaria também estruturado no desenvolvimento das tecnologias da informação, e no aumento da intensidade e precariedade do trabalho humano. Já Cutrim e Léda (2016) destacaram a transformação da quase sempre administração familiar do negócio, para a financeira, em algumas das maiores IES privadas com fins lucrativos no país.

Algumas obras do autor podem ser consultadas em Chesnais (1996, 2005). 
Mesmo que membros das tradicionais famílias que comandavam algumas grandes companhias de capital aberto, ainda façam parte da sua administração, a inserção de profissionais especializados nos negócios dos mercados financeiros passou a ser uma necessidade para a ampliação da eficiência na gestão corporativa.

Assim, com a introdução de diferenciados atores na gestão empresarial do segmento, tais como os fundos de investimentos, executivos especializados no assunto, alguns bancos, universidades estrangeiras, ou os novos acionistas pelas vias do mercado financeiro exigiram a implantação de um modelo associado às grandes corporações.

No Brasil, a Instrução n 391/2003 da Comissão de Valores Mobiliários (CVM) dispôs sobre a constituição, o funcionamento e a administração dos Fundos de Investimento em Participações (BRASIL, 2003). A CVM, a Lei n 6.385/1976 (BRASIL, 1976a), a Lei n 6.404/1976 (BRASIL, 1976b), o Conselho Monetário Nacional (CMN) e o Banco Central do Brasil (BACEN) regulam o mercado de valores mobilírios no país, a primeira supervisiona e edita normas gerais sobre o poder disciplinar da BM\&FBovespa e das instituições financeiras junto a ela registradas. Os dois últimos podem, entre outras atribuições, permitir a constituição e o funcionamento das corretoras de valores mobiliários, bem como regulamentar operações de câmbio e investimentos estrangeiros.

Já Sarfati e Shwartzbaum (2013), e Polizel e Steinberg (2013, p. 11-12), ao discordarem das críticas imputadas ao processo de financeirização do capital no ensino superior do setor privado com fins lucrativos, afirmaram que a ampliação da profissionalização da gestão nas companhias, particularmente as de capital aberto, tem trazido vantagens para a educação como um todo, melhorando não só as questões administrativas, com a superação de antigos problemas, mas também ampliando a qualidade nos espaços acadêmicos. Assim, elencaram 9 pontos sobre os benefícios das práticas de gestão corporativa, como:

1. Economia de escala com a constante padronização e integração de
processos; 2. Maior controle de custos, fruto de uma gestão mais profissional;
3. Menores valores de mensalidades, reflexo da redução de custos; 4.
Políticas mais agressivas de comunicação e marketing; 5. Maior potencial
de recursos para investimentos; 6. Consolidação, concentração de grande
número de alunos; 7. Acesso a capital de baixo custo; 8. Padronização de
processos; 9. Acesso facilitado (menor custo) a recursos metodológicos e
didáticos. (POLIZEL; STEINBERG, 2013, p. 11-12).

$\mathrm{Na}$ área educacional, fora a recente profissionalização da gestão administrativa no ramo de algumas empresas, o que as leva a um processo de amadurecimento nos próximos anos, de acordo com Bonventti (2008), a união entre a qualidade no ensino e a 
gestão corporativa serão os fatores essenciais para o sucesso financeiro das IES do setor privado no país.

0 aumento no número de sócios nas $\mathbb{E}$ S do setor privado com fins lucrativos que abriram seu capital na bolsa de valores, constituiu-se como uma das condições para entrar no mercado de ações. Além da dispersão acionária no mercado de ações da BM\&FBovespa, que envolve desde o pequeno até o grande acionista, ou sócios das companhias, ressalta-se a participação de grandes fundos de investimentos, nacionais e estrangeiros, na reorganização e condução dos negócios da Anhanguera, Estácio e Kroton. Esses fundos se tornaram os principais, ou o principal acionista de várias grandes empresas de ensino superior privado com fins lucrativos no Brasil, na última década.

Os Fundos de Equidade Privada, pela quantidade de ações que passaram a obter das companhias de capital aberto no ensino superior, depois de sua alta valorização no mercado de ações conseguiram obter boas somas de lucros com o investimento, quando vários deles venderam, ou mesmo depois voltaram a comprar ações das IES. Como tem estrutura para trabalhar com volume expressivo de ações, após a valorização dos papéis na bolsa, conseguiram e tem conseguido movimentar elevadas somas de capitais.

Se, como veremos adiante, o crescimento no número de matrículas chamou a atenção, para a Anhanguera, Estácio e Kroton, de 2007 a 2014, em boa parte desse período, os índices de valorização anuais nos papéis das duas companhias no mercado de ações ultrapassou e muito os números estimados para a inflação, constituindo-se como ótima opção de investimento. No entanto, certos fatores fizeram com que os preços das ações, em determinados momentos, oscilassem para baixo, ao apresentar desvalorização dos títulos, como foi o caso quando das mudanças no Fies, no começo de 2015.

Sobre essas novas parcerias no mundo do mercado financeiro, entre grandes empresas de ensino superior com fins lucrativos no Brasil (de capital aberto ou fechado) e Fundos de Equidade Privada, Carvalho (2012, p. 770) colocou a que foi feita entre o Pátria Investimentos ${ }^{7}$ e a Anhanguera; o GP Investments ${ }^{8}$ e a Estácio; o Advent International ${ }^{\beta}$ e a Kroton; - Catesian Capital Group ${ }^{10}$ e a Faculdade Maurício de Nassau (parte do Grupo Ser Educacional).

Se, em 2009, o Advent International investiu aproximadamente US\$ 141 milhões na Kroton, em 2013, vendeu sua participação por US\$ 1 bilhão, uma valorização de 609,2\%, no período de quatro anos (SGUISSARDI, 2014). Outra estratégia dentro das novas formas

\footnotetext{
7 Fundo de Equidade Privada, brasileiro, que atua na América Latina, com o foco em negócios como Infraestrutura, Imobilírio, Crédito, Agronegócio, e outros. Fonte: http://www.patria.com.

8 Atua na gestão de recursos de Fundos de Equidade Privada, com forte atuação na América Latina. Tem sede nas llhas Bermudas, um território ultramarino inglês no Caribe. Fonte: http://www.gp.com.br.

9 Atua na gestão de recursos de Fundos de Equidade Privada. Fonte: https://www.adventinternational.com.

10 Fundo de Equidade Privada que atua em mais de 24 paises do planeta. Fonte: https://cartesiangroup.com.
} 
de gestão corporativa de muitas companhias de ensino superior do setor privado com fins lucrativos, no país, de 2007 a 2014, consistiu nas aquisições e fusões realizadas por elas. Como já colocado, a própria Kroton e a Anhanguera efetivaram definitivamente seu processo de incorporação, no último ano.

De 2007 a 2012, o número de aquisições e fusões para as três companhias chegou a 78, e um valor de $\mathrm{R} \$ 4,2$ bilhões (sem correção monetária). A Anhanguera adquiriu 38 IES e gastou R\$1,64 bilhão; a Estácio, 21 IES, com o gasto de R $\$ 250,5$ milhões; além da Kroton, com 19 IES, e o investimento de R\$2,32 bilhões (COSTA, 2016).

No texto de Sarfati e Shwartzbaum (2013, p. 5), trabalhou-se com a hipótese, que foi corroborada, de que as aquisições e fusões estariam a gerar sinergias para as companhias, com a obtenção de boas margens de lucros para seus acionistas, bem como melhor organização nos seus grupos de executivos. Os autores pretenderam identificar "quais seriam as potenciais sinergias específicas do setor, discutindo quatro principais efeitos: (i) aumento de receitas, (ii) redução de custos e despesas, (iii) benefícios fiscais e (iv) redução dos custos de capital".

Ainda que algumas poucas IES tenham sido alienadas na Anhanguera, Estácio e Kroton, ao longo dos anos de 2007 a 2012, como mostrou Costa (2016), no conjunto das fusões e aquisições para o período, o que inclui os anos de 2013 e 2014, os benefícios acumulados para os acionistas, com a valorização das ações e distribuição de dividendos, constituíramse como uma das melhores opções de investimento no mercado nacional, e que chamou a atenção também do mercado internacional.

A Estácio iniciou sua negociação de American Depositary Receipts (ADR's), em mercados de balcão dos Estados Unidos, em 2014. 0 objetivo consistiu em elevar a liquidez acionária da companhia, com o crescimento no número de acionistas e a criação de alternativas de negociação para seus títulos de propriedade. No caso da Kroton, começou a negociar suas ações ordinárias nesse país, em outubro de 2013.

0 processo de oligopolização que estaria a ocorrer no ensino superior privado brasileiro (CARVALHO, 2012; OLIVEIRA, 2017; SGUISSARDI, 2014), por meio do aumento constante de matrículas nas maiores IES do setor privado com fins lucrativos, acaba levando à concentração de mercado, com a imposição de concorrência desleal frente às menores $\mathbb{E} S$, que podem vir a apresentar maiores dificuldades em competir com as grandes companhias.

Os dados mostrados a seguir nos permitem compreender melhor os argumentos apresentados nessa seção. 0 Gráfico 1, abaixo, mostra o desempenho da Anhanguera, Estácio e Kroton, nos anos de 2010, 2013 e 2014, em relação ao total de matrículas no ensino superior (público e privado), bem como em relação ao total de matrículas no ensino superior privado brasileiro, ambos tendo em conta as matrículas presenciais e a distância. 
Gráfico 1 - Participação no número de matrículas (\%), da Anhanguera, Estácio e Kroton, em relação ao total de matrículas no ensino superior brasileiro, bem como em relação ao setor privado, em 2010, 2013 e 2014

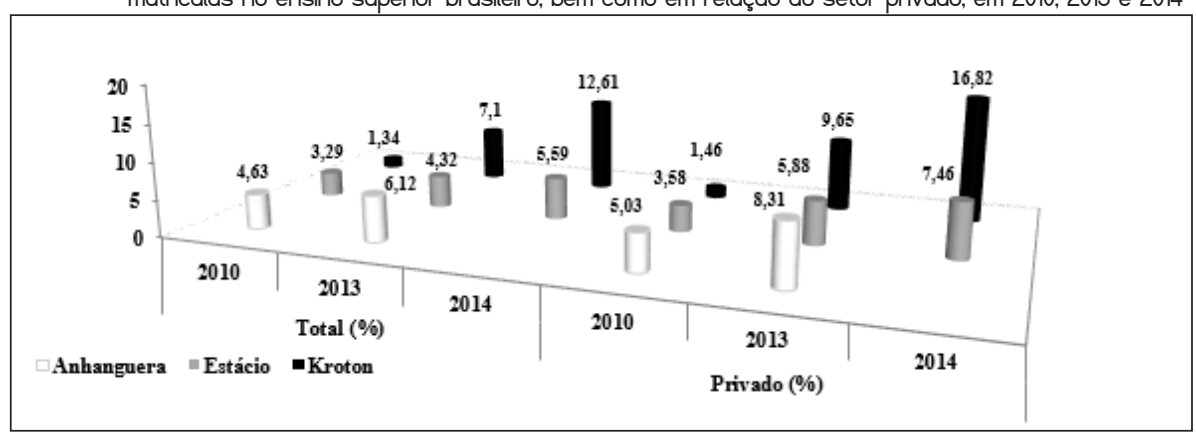

Fonte: elaborado pelo autor com base em Estácio (2014, 2015) e Kroton (2014, 2015).

Em 2014, a Estácio e Kroton concentraram aproximadamente $24,28 \%$ de todas as matrículas no setor privado, e $18,2 \%$ de todas as matrículas no ensino superior brasileiro, 0 que evidencia a tendência de oligopolização. Com o forte crescimento da Kroton, ainda nesse ano, apresentou mais do que o dobro de participação nas matrículas, tanto em relação ao total quanto em relação apenas ao setor privado, se comparada à Estácio, sua concorrente mais próxima.

Muitas $\mathbb{E}$ foram adquiridas pela Kroton, que executou no período uma gestão corporativa mais agressiva para seu crescimento, quando comparada à Estácio. Desde 2007, a primeira companhia adquiriu grandes empresas que atuavam majoritariamente no ensino a distância, como a Unopar e Uniasselvi, além da fusão com a Anhanguera, em 2014. Se, em 2010, a participação da Kroton no total de matrículas no setor privado foi de aproximadamente 1,46\%, em 2014 , chegou a $16,82 \%$. Apenas com o crescimento orgânico, sem as fusões e aquisições realizadas pela companhia, não teria sido possível obter a destacada expansão (SARFAT); SHWARTZBAUM, 2013).

A Kroton lançou informação sobre sua base de alunos diversificada, em julho de 2014, com mais de 1,5 milhão de matrículas, distribuídas no ensino superior (com atuação em 544 municípios), cursos preparatórios, cursos técnicos, cursos livres e de educação básica. Em 2013, o número de trabalhadores na Estácio foi de aproximadamente 12,3 mil, e na Anhaguera, 17,2 mil. Depois da fusão com a Kroton, em 2014, seu número de trabalhadores subiu para 37 mil (ESTÁCIO, 2014; KROTON, 2015).

Para consolidar a fusão entre as duas companhias, o Conselho Administrativo de Defesa Econômica (CADE) (Ministério da Fazenda), exigiu algumas medidas da Kroton, como a venda da Uniasselvi, comprada em 2012, por cerca de $\mathrm{R} \$ 510$ milhões, e vendida a grandes 
Fundos de Equidade Privada, por R\$ 1,1 bilhão, em 2015. Ainda, a alienação de outras duas IES que ofereciam cursos presenciais em Cuiabá e Rondonópolis; impôs limites na captura de matrículas em cursos de educação a distância de 48 municípios, até 2017; bem como a companhia decidiu não usar suas marcas para registrar novas matrículas de determinados cursos de ensino a distância, em municípios nos quais ela e a Anhanguera atuassem.

Na Tabela 1, mostram-se os dados para o número de matrículas nas três, e depois duas companhias selecionadas, apenas no ensino presencial, de 2007 a 2014. Para a Kroton, o crescimento foi de aproximadamente $2.346,4 \%$, e para a Estácio, $77,6 \%$.

Tabela 1 - Número de matrículas no ensino presencial, na Anhanguera, Estácio e Kroton, de 2007 a 2014

\begin{tabular}{lcccccccr}
\hline & 2007 & \multicolumn{1}{c}{2008} & \multicolumn{1}{c}{2009} & \multicolumn{1}{c}{2010} & \multicolumn{1}{c}{2011} & \multicolumn{1}{c}{2012} & \multicolumn{1}{c}{2013} & \multicolumn{1}{c}{2014} \\
\hline Anhanguera & 78.283 & 122.315 & 148.130 & 163.996 & 216.375 & 284.720 & 306.000 & - \\
Estácio & 186.800 & 207.000 & 196.100 & 183.800 & 200.600 & 222.600 & 255.000 & 331.700 \\
Kroton & 17.997 & 42.491 & 43.612 & 85.367 & 108.283 & 143.216 & 167.151 & 440.284 \\
\hline
\end{tabular}

Fonte: elaborada pelo autor com base em Estácio $(2014,2015)$ e Kroton $(2014,2015)$.

A fusão com a Anhanguera permitiu que a Kroton ultrapassasse a Estácio, em 2014, no que tange ao número de matrículas no ensino presencial, em aproximadamente $32,7 \%$, ao alcançar a marca de 440.284 alunos. Em 2013, a Estácio possuía 19 empresas no grupo, das quais 16 mantenedoras de IES, o que abrangia 1 universidade, 7 centros universitários e 36 faculdades, espalhadas por 22 estados, mais o Distrito Federal, no Brasil. No ano seguinte, a companhia anunciou sua atuação em todos os estados da federação, a inauguração de 2 centros universitários, um em Belo Horizonte, e outro em Goiânia, além do sucesso nas suas diversas formas de parcerias.

Uma delas consistiu na criação de sua Universidade Corporativa, com o objetivo de melhorar o desempenho dos trabalhadores e da própria IES; um Projeto Corporativo, em associação com várias grandes empresas atuantes em diversos setores da economia, para a qualificação dos seus trabalhadores; a parceria com universidades estrangeiras; capacitação dos mais de $१ 20$ mil voluntários que trabalharam nos Jogos Olímpicos, os quais ocorreram em 2016; ganhou os editais de transferência assistida da Universidade Gama Filho e UniverCidade, na cidade do Rio de Janeiro; bem como o trabalho conjunto com outras grandes companhias do setor privado, em busca de ganhos para o setor, por meio da Associação Brasileira para o Desenvolvimento do Ensino Superior (ABRAES), do Fórum das Entidades Representativas do Ensino Superior Particular, ou da Associação Brasileira de Mantenedoras do Ensino Superior (ABMES), para citar alguns. 
Para o ensino a distância, a Tabela 2 mostra os números para as matrículas das 3 companhias, de 2007 a 2014. 0 aumento na Kroton foi de aproximadamente 278,0\%, de 2011 a 2014, enquanto na Estácio, de 1.001,0\%, em virtude principalmente das aquisições realizadas no período, em ambas.

Tabela 2 - Número de matrículas no ensino a distância, na Anhanguera, Estácio e Kroton, de 2007 a 2014

\begin{tabular}{lrrrrrrrr}
\hline & \multicolumn{1}{c}{2007} & \multicolumn{1}{c}{2008} & \multicolumn{1}{c}{2009} & \multicolumn{1}{c}{2010} & \multicolumn{1}{c}{2011} & \multicolumn{1}{c}{2012} & 2013 & \multicolumn{1}{c}{2014} \\
\hline Anhanguera & 13.969 & 90.756 & 107.053 & 131.031 & 144.581 & 144.356 & 140.800 & - \\
Estácio & - & - & 9.600 & 26.200 & 39.400 & 48.000 & 60.700 & 105.700 \\
Kroton & - & - & - & - & 144.581 & 216.819 & 351.357 & 546.543 \\
\hline
\end{tabular}

Fonte: elaborada pelo autor com base em Estácio $(2014,2015)$ e Kroton $(2014,2015)$.

Com a expansão na oferta de ensino superior a distância, para as classes de menor poder econômico, tal qual a que tem ocorrido nos últimos anos, ou com a necessidade de formação de professores no país, para atuação na educação básica, o custo sobre o capital das empresas diminuiu com a não necessidade de abertura de novos cursos de graduação ou novas IES. As próprias mensalidades se apresentaram como possíveis de pagamento para um novo público que ingressou nesse nível de ensino.

A Kroton forneceu os dados para a renda familiar de sua clientela no ensino superior, em relação ao ano de 2013. Assim, 29\% das matrículas estavam enquadradas em níveis de renda de 1 a 2 salários mínimos, $32 \%$, de 3 a 4 salários mínimos, $16 \%$, de 5 a 6 salários mínimos, $9 \%$, de 7 a 8 salários mínimos, $6 \%$, de 9 a 10 salários mínimos, e $8 \%$, acima de 10 salários mínimos (KROTON, 2014).

De acordo com Ghirardi e Klafke (2017), a expansão das matrículas no ensino a distância para as IES do setor privado com fins lucrativos, e com capital aberto na BM\&FBovespa, cresceu aproximadamente $657,7 \%$, de 2010 a 2014 , quando passou de 87.915 , no primeiro ano, para 666.146, no último. Em relação ao total, o crescimento no ensino a distância foi de 44,3\%, ao sair de 930.179, para 1.341 .842 matrículas, no período observado. A participação desses grupos em relação ao total de matrículas na modalidade de ensino passou de 9,5\%, para $49,6 \%$, no último ano.

A formação das grandes companhias de ensino superior no país, segundo os autores acima, leva à preocupação apontada pela crítica, da pressão exercida por essas instituições sobre as políticas educacionais, por meio dos parlamentares e seus partidos políticos, bem como sobre a qualidade do ensino, diante de modelos educacionais padronizados, cujas metas têm procurado atender, minimamente, as diretrizes colocadas pelo Ministério da 
Educação (MEC), a exemplo do Sistema Nacional de Avaliação da Educação Superior (SINAES), que aufere qualidade para as instituições e os cursos de ensino superior.

Se os requisitos para determinar a qualidade no ensino superior consistem em alcançar índices acima de 3 nos parâmetros colocados pelo SINAES, numa escala de 1 a 5 , então é possível afirmar que a Anhanguera, Estácio e Kroton melhoraram seus conceitos diante dos números, conforme apresentado pelas próprias companhias em documentos anexados nos endereços eletrônicos das suas relações com investidores

Para a divulgação e consolidação da marca, a propaganda e o marketing constituem outras estratégias de importância nas regras da governança corporativa, para as grandes companhias de ensino superior no setor privado com fins lucrativos no país. Quando do aval e reconhecimento por parte do MEC, para o credenciamento e recredenciamento dessas IES e seus cursos, com notas satisfatórias em seus parâmetros de avaliação e regulação, a Kroton, para o ano de 2013, afirmou-se como a mais bem colocada no ENADE, entre as companhias de capital aberto na bolsa de valores, e com $80 \%$ de seus cursos com conceitos satisfatórios (KROTON, 2014, p. 2).

0 próximo conjunto de dados trata de certos pontos ligados às questões financeiras das 3 companhias. A Tabela 3 mostra a Receita Bruta, de 2007 a 2014 . Na Anhanguera, o crescimento foi de aproximadamente $815,40 \%$, de 2007 a 2013, enquanto nas outras duas, ao incluir o ano de 2014, chegou a 167,2\% na Estácio, e 5.827,1\% na Kroton.

Tabela 3 - Receita Bruta na Anhanguera, Estácio e Kroton, de 2007 a 2014 (R\$ milhões).

\begin{tabular}{lrrrrrrrr}
\hline & \multicolumn{1}{c}{2007} & \multicolumn{1}{c}{2008} & \multicolumn{1}{c}{2009} & \multicolumn{1}{c}{2010} & \multicolumn{1}{c}{2011} & \multicolumn{1}{c}{2012} & 2013 & 2014 \\
\hline Anhanguera & 347,2 & 905,1 & $1.329,8$ & $1.530,8$ & $1.981,3$ & $2.547,1$ & $3.178,2$ & - \\
Estácio & $1.278,4$ & $1.432,3$ & $1.459,8$ & $1.454,3$ & $1.632,1$ & $1.971,9$ & $2.491,0$ & $3.416,0$ \\
Kroton & 79,3 & 209,2 & 395,1 & 582,6 & 737,2 & $1.557,4$ & $2.443,0$ & $4.700,2$ \\
\hline
\end{tabular}

Fonte: elaborada pelo autor com base em Estácio (2014, 2015) e Kroton (2014, 2015).

Depois da incorporação com a Anhanguera, de 2013 para 2014, a Receita Bruta da Kroton aumentou aproximadamente $92,4 \%$, quando ultrapassou a casa dos $R \$ 4,7$ bilhões. Isso tendo em conta que, nos dados, apenas os últimos seis meses do ano foram levados em consideração (KROTON, 2015).

A força que a renúncia fiscal, por meio do PROUNl, e principalmente as bolsas de estudos com o FIES, de 2010 a 2015, passou a exercer nas grandes companhias de ensino superior, determinaram um incremento importante nas suas receitas. 0 s gastos de recursos financeiros públicos com esse último saltaram de $R \$ 1$ bilhão, em 2010, para $R \$ 13$ bilhões, em 
2014. Desses mais de $R \$ 13$ bilhões, cerca de $R \$ 2,6$ bilhões teriam ido para IES com índices insatisfatórios nas avaliações do MEC (NAPOLITANO, 2017).

Na Kroton, o número de alunos com bolsa do FIES passou de 3.506, no primeiro semestre de 2010, para 89.856, no quarto trimestre de 2013, ou seja, um aumento de aproximadamente $2.465,8 \%$, cuja Receita Liquida chegou a $\mathrm{R} \$ 718,6$ milhões. Em 2014, as bolsas chegaram a 258.974 matrículas, o que correspondeu a 61,2\% da base de alunos da graduação presencial na companhia, ou $26,2 \%$ de todas as suas matrículas, com uma Receita Líquida de R\$ 1,8 bilhão (KROTON, 2014, 2015).

Para a Estácio, o número de matrículas com bolsas no FIES chegou a 76,1 mil, em 2013 , o que representou aproximadamente $29,8 \%$ da sua base de alunos no ensino presencial, com uma Receita Líquida de $\mathrm{R} \$ 423,8$ milhões. No ano de 2014 , as matrículas subiram para 122,7 mil, ou 37,0\% da base de matrículas no ensino superior presencial (ESTÁCI0, 2014, 2015).

Enquanto as somas de capitais saíam dos recursos financeiros públicos para várias IES do setor privado, em especial para aquelas com capital aberto, a desvalorização de seus papéis no mercado de ações só veio a apresentar significativa oscilação quando das transformações promovidas no FIES, no começo de 2015. No final de 2014, depois de reeleita, Dilma Rousseff, com sua nova equipe econômica, prenunciou a necessidade de mudanças na liberação de recursos para o FIES. Dessa forma, de novembro de 2014 a março de 2015, os papeis da Kroton sofreram desvalorização de aproximadamente 41\%, e os da Anima Educação, 54\% (BURGARELLI, 2017).

Agora, Sarfati e Shwartzbaum (2013) colocaram que os gastos de recursos financeiros públicos no Brasil, com o ensino superior privado, quando comparado com países da Organização para Cooperação e Desenvolvimento Econômico (OCDE), seria 3 vezes e meio menor, com apenas 0,08\% do Produto Interno Bruto (PIB).

Outra medida do governo Dilma foi inserir o Programa Nacional de Acesso ao Ensino Técnico e Emprego (PRONATEC) no ensino superior privado, em especial nas grandes companhias de capital aberto. A Kroton começou a oferecer cursos técnicos, pela modalidade Bolsa Formação, com bolsas de estudos financiadas integralmente pelos recursos financeiros públicos.

Em 2013, a companhia encerrou o ano com mais de 5.000 matrículas, e esperava 14.000 para o ano seguinte. Apenas para os meses de setembro e outubro de 2013, a arrecadação com o programa foi de aproximadamente $R \$ 4,8$ milhões. No entanto, o sucesso do PRONATEC na Kroton foi grande, e em 2014, encerrou o ano com 36,9 mil matrículas, em 49 cursos (KROTON, 2014, 2015).

Na Estácio, o início da oferta do PRONATEC também ocorreu em 2014, com a aprovação de 24 mil vagas, captação de 19,6 mil matrículas e arrecadação bruta de $R \$ 64,1$ milhões. Para o 
PROUNl, na Kroton, as deduções fiscais com o programa chegaram a R\$530,7 milhões, em 2014; já na Estácio, a R\$ 145,8 milhões, no mesmo período (ESTÁCI0, 2015; KROTON, 2015).

Com a Tabela 4 são apresentados os dados dos Custos dos Serviços Prestados, de 2007 a 2014, para as 3 companhias. Com relação à Anhanguera, de 2007 a 2013, o crescimento foi ininterrupto e chegou a aproximadamente 590,0\%. Para a Estácio, de 2007 a 2014 , alcançou $141,7 \%$.

Tabela 4 - Custo dos Serviços Prestados na Anhanguera, Estácio e Kroton, de 2007 a 2014 (R\$ milhões)

\begin{tabular}{lrrrrrrrr}
\hline & \multicolumn{1}{c}{2007} & \multicolumn{1}{c}{2008} & \multicolumn{1}{c}{2009} & \multicolumn{1}{c}{2010} & \multicolumn{1}{c}{2011} & 2012 & 2013 & 2014 \\
\hline Anhanguera & 151,6 & 389,4 & 524,6 & 559,9 & 695,7 & 971,7 & $1.046,0$ & - \\
Estácio & 539,8 & 599,7 & 651,2 & 697,0 & 756,5 & 877,4 & 987,9 & $1.304,5$ \\
Kroton & 69,0 & 179,9 & 230,9 & 376,3 & 462,9 & 736,9 & 855,3 & $1.229,1$ \\
\hline
\end{tabular}

Fonte: elaborada pelo autor com base em Estácio (2014, 2015) e Kroton (2014, 2015).

Com a Receita Bruta e a Receita Líquida da Kroton já bem maior do que a da sua principal concorrente, a Estácio, em 2014, observa-se que seu Custo dos Serviços Prestados ainda foi menor, quando da comparação entre ambas, ao se constituir como um dos pontos de maior sucesso em suas estratégias de gestão corporativa. 0 que não diminuiu foi o gasto com o grupo de principais executivos da Kroton. Em 2013, na comparação com 2012, o aumento foi de aproximadamente $81,8 \%$, ao passar de $R \$ 14,9$ milhões, para $R \$ 27,1$ milhões.

Para Gramani (2008), muitos fatores podem vir a ser priorizados, quando uma grande IES com fins lucrativos passa a almejar a redução de seus custos anuais, como no caso da contratação, demissão ou incentivos à qualificação de trabalhadores na companhia; criação e desenvolvimento de programas curtos para maximizar os lucros; avaliação do corpo docente de acordo com as necessidades impostas pelos consumidores; padronização dos currículos; queda nos investimentos em infraestrutura, como bibliotecas, laboratórios e materiais; ou ainda, redução no financiamento de pesquisa científica.

A padronização curricular, que para a crítica é tida como minimalista e uniformizada, para os executivos das grandes companhias de capital aberto apresenta boas vantagens para a rentabilidade das IES, principalmente depois da aquisição de unidades de ensino e cursos que não atendem às exigências do MEC, já que após a aquisição, o novo currículo deixa os custos dos serviços prestados mais baratos e rentáveis. $\mathrm{Na}$ Estácio, a "Integração curricular nacional acrescenta mobilidade e flexibilidade total ao modelo acadêmico" (ESTÁCIO, 2015). 
Pelos dados de Malvessi (2017), a participação da remuneração dos professores sobre a Receita Líquida, de 2011 a 2015, na Kroton, saiu de aproximadamente 48\%, no primeiro ano, para $31 \%$, no último. Na Estácio, respectivamente, de $48 \%$ para $41 \%$. Como consequências desse processo de redução no número de docentes, nas grandes companhias de ensino superior de capital aberto, como a Kroton e Estácio, a crítica aponta o aumento da exploração sobre os trabalhadores, por parte do capital.

Isso poderia ser visto, no caso, com o aumento na jornada de trabalho e rotatividade dos professores; demissão de docentes depois dos processos de fusões e aquisições"; crescimento da relação professor e aluno; queda na politização, profissionalização e autonomia da categoria; pequenos índices de produtividade em pesquisa e extensão; professores com titulação suficiente para atender às exigências legais, caso atendam; menos funções docentes em tempo integral, quando comparadas com o setor público, além de alta flexibilidade nos contratos de trabalhos; baixo valor pago por hora-aula; elevada concorrência; etc. (ÁVILA, 2010; CUTRIM; LÉDA, 2016; SGUISSARDI, 2014; VALE, 2011).

Quanto ao Lucro Bruto, na Tabela 5, ainda que não se possa afirmar um aumento contínuo para todas as companhias, no período observado, em virtude da Estácio, nos anos de 2009 e 2010, a expansão seguiu a mesma tendência dos demais dados até aqui apresentados. Com isso, para essa companhia, de 2007 a 2014, o aumento foi de aproximadamente $221,1 \%$. Já na Anhanguera, de 2007 a 2013 , chegou a $528,4 \%$.

Tabela 5 - Lucro Bruto na Anhanguera, Estácio e Kroton, de 2007 a 2014 (R\$ milhões)

\begin{tabular}{lrrrrrrrr}
\hline & \multicolumn{1}{c}{2007} & \multicolumn{1}{c}{2008} & \multicolumn{1}{c}{2009} & \multicolumn{1}{c}{2010} & \multicolumn{1}{c}{2011} & 2012 & 2013 & 2014 \\
\hline Anhanguera & 122,0 & 264,8 & 379,9 & 444,0 & 536,4 & 635,6 & 766,7 & - \\
Estácio & 320,3 & 388,4 & 357,6 & 323,9 & 382,9 & 505,9 & 694,5 & $1.028,6$ \\
Kroton & 68,1 & 99,6 & 122,1 & 202,0 & 258,2 & 620,0 & $1.160,7$ & $2.545,3$ \\
\hline
\end{tabular}

Fonte: elaborada pelo autor com base em Estácio $(2014,2015)$ e Kroton $(2014,2015)$.

Para o Lucro Líquido, pode-se dizer que mostrou as maiores oscilações, entre todos os dados colocados até aqui, como coloca a Tabela 6. Apenas a Estácio não apresentou números negativos, de 2007 a 2014. Na Anhanguera, isso ocorreu em 2008, e na Kroton, em 2009 e 2010.

A Kroton divulgou como um dos sucessos na sua gestão corporativa, para a integração com o Grupo IUNl, a demissão de 1.079 funcionários, com importante impacto na redução de custos e despesas da companhia. 
Tabela 6 - Lucro Líquido na Anhanguera, Estácio e Kroton, de 2007 a 2014 (R\$ milhões).

\begin{tabular}{|c|c|c|c|c|c|c|c|c|}
\hline & 2007 & 2008 & 2009 & 2010 & 2011 & 2012 & 2013 & 2014 \\
\hline Anhanguera & 0,4 & $-26,7$ & 64,3 & १२२, & 42,1 & 152,0 & 125,4 & - \\
\hline Estácio & 61,1 & 37,6 & 66,2 & 80,7 & 70,2 & 109,7 & 244,7 & 425,6 \\
\hline Kroton & 19,9 & 32,9 & $-8,1$ & $-29,6$ & 37,4 & 202,0 & 582,4 & $1.216,3$ \\
\hline
\end{tabular}

Fonte: elaborada pelo autor com base em Estácio (2014, 2015) e Kroton (2014, 2015).

Se levarmos em consideração os números para a Kroton, de 2007 a 2014, o aumento chegou a aproximadamente $6.102,1 \%$. A não distribuição de dividendos na companhia para seus acionistas, em virtude dos prejuízos, em 2009 e 2010, acabou por ser compensada nos anos de 2013 e 2014, principalmente quando a $\mathbb{E} E S$ liderou os índices de lucratividade na BM\&FBovespa, entre todas as companhias no mercado de ações. Para 2013, a alta chegou a aproximadamente $69,8 \%$, e a companhia, com um valor de mercado de $R \$ 10,5$ bilhões, nesse ano, passou a integrar o mais importante índice da BM\&FBovespa, o IBOVESPA, que calcula o desempenho médio das ações mais negociadas nesse mercado, nos últimos meses. Contudo, no mesmo período, para esse índice, a desvalorização atingiu 15,5\% (KROTON, 2014).

Em 2014, na Kroton, o volume médio negociado nos pregões da BM\&FBovespa atingiu aproximadamente $\mathrm{R} \$ 176,5$ milhões (169,1\% maior do que no ano anterior), e a companhia foi estimada com um valor de mercado de $R \$ 25,2$ bilhões (140\% maior do que em 2013). Sua valorização ao longo do ano atingiu 61,5\%, no Novo Mercado, ao liderar novamente o mercado de ações, com o maior índice, enquanto o IBOVESPA, novamente apresentou queda de 0,7\%.

A estrutura acionária da maior empresa de educação do planeta passou a ter os fundadores da UNOPAR como seus maiores acionistas, com 6,0\% de todas elas, seguidos pelo Advent International $(5,8 \%)$, os fundadores do Grupo Pitágoras $(5,8 \%)$, os fundadores da Anhanguera (4,4\%), os fundadores da IUNI (2,1\%), além de outros acionistas (75,9\%).

Muitos programas de recompra de ações, com o objetivo de gerar valorização para os acionistas, foram feitos pela Estácio e Kroton, desde as suas aberturas de capitais na bolsa de valores. No ano de 2013, o custo dessa despesa para a segunda companhia foi de aproximadamente $\mathrm{R} \$ 18,4$ milhões. Em 2014 ocorreu mais um programa de recompra; três aumentos de capitais, que deram origem a 1.623 .795 .559 ações ordinárias; além do desdobramento de ações ordinárias da companhia, de 1 para 4 , com o reposicionamento de preços das ações considerados mais atraentes aos investidores.

Os Planos de Opções de Ações continuaram a ocorrer na Estácio e Kroton, nos anos de 2013 e 2014, como uma das estratégias, sobretudo para estreitar os laços entre os principais executivos e as companhias. A Estácio, por exemplo, contou no último ano, 
com outro programa, o de Remuneração, que abrangeu os trabalhadores administrativos da instituição, com exceção dos estagiários, menores aprendizes e terceiros.

Na Estácio, a valorização de suas ações na BM\&FBovespa, no Novo Mercado, foi de aproximadamente $47,6 \%$, em 2013 , com um volume médio de negociações diário de $R \$ 43,7$ milhões, ou $257 \%$ maior do que no ano anterior. Em 2014, chegou a $16,7 \%$, a valorização dos títulos. 0 lucro líquido por ação foi de $R \$ 0,83$, na distribuição dos dividendos anuais, e seu valor de mercado esteve estimado em $\mathrm{R} \$$ 6,6 bilhões, no ano de 2013; em 2014, o lucro por ação foi de $\mathrm{R} \$ 1,35$ (ESTÁCIO, 2014, 2015).

Além disso, a Estácio realizou um OPA em janeiro de 2013, cuja arrecadação, de $\mathrm{R} \$$ 768,7 milhões, originada da distribuição primária e secundária de ações ordinárias de emissão da companhia, foi essencial para as aquisições realizadas; cancelou sua linha de crédito com o IFC, no valor de R\$ १२२,6 milhões; bem como inaugurou mais três unidades (greenfields), em Angra dos Reis, Teresópolis e Fortaleza.

Em 2014, ocorreu a $2^{a}$ emissão de debêntures, não conversíveis em ações, com vencimento de 5 anos, cuja arrecadação foi de R\$300 milhões, na Estácio. Ainda nesse ano, a companhia adquiriu a IESAM, por aproximadamente $\mathrm{R} \$ 80$ milhões, com 4.500 alunos, no Pará; a LITERATUS, por R\$21,8 milhões e 4.800 alunos, no Amazonas; bem como a CEUT, por R\$33 milhões e 3.700 alunos, no Piauí.

Por fim, o Patrimônio Líquido das 3 companhias, de 2007 a 2014, segue conforme a Tabela 7. De 2007 a 2013, na Anhanguera, seu crescimento alcançou aproximadamente 380,5\%, e na Estácio, 490,1\%. No caso da Kroton, de 2007 a 2014, a expansão foi de aproximadamente 2.516,3\%, e apenas de 2013 para 2014, de 337,1\%, depois da incorporação com a Anhanguera. Quando comparada à Estácio, seu Patrimônio Líquido, no último ano, foi aproximadamente $378,3 \%$ maior do que a de sua concorrente mais próxima.

Tabela 7 - Patrimônio Líquido na Anhanguera, Estácio e Kroton (2007 a 2014 - R\$ milhões).

\begin{tabular}{lcrrrrrrr}
\hline & \multicolumn{1}{c}{2007} & \multicolumn{1}{c}{2008} & \multicolumn{1}{c}{2009} & \multicolumn{1}{c}{2010} & \multicolumn{1}{c}{2011} & \multicolumn{1}{c}{2012} & \multicolumn{1}{c}{2013} & \multicolumn{1}{c}{2014} \\
\hline Anhanguera & 484,4 & 977,9 & $1.050,7$ & $2.005,3$ & $2.005,6$ & $2.209,1$ & $2.327,3$ & - \\
Estácio & 405,5 & 421,1 & 458,0 & 585,9 & 618,9 & 707,0 & $1.517,6$ & $2.392,9$ \\
Kroton & 437,5 & 455,1 & 795,1 & 816,2 & $1.475,3$ & $2.246,6$ & $2.618,7$ & $11.446,4$ \\
\hline
\end{tabular}

Fonte: elaborada pelo autor com base em Estácio (2014, 2015) e Kroton (2014, 2015).

Os dados operacionais e financeiros da Anhanguera, Estácio e Kroton, em toda a série temporal analisada, permitiram observar como o ensino superior privado, em especial com as companhias de capital aberto, constituiu-se como excelente opção de investimento, no 
mercado de ações, ao apresentar boas margens de lucro. Nas considerações finais, adiante, alguns dos principais resultados do trabalho.

\section{CONSIDERAÇÕES FINAIS}

A fusão da Anhanguera e Kroton alterou de forma significativa os dados operacionais e financeiros dessa última, em 2014, que foi o primeiro ano apresentado após a associação entre ambas. Assim, a tendência de oligopolização, ou concentração de mercado, tornou-se uma realidade, pelos números que foram mostrados ao longo do texto. Apenas a Kroton, no ano de 2014 , englobou quase $13,0 \%$ de todas as matrículas no ensino superior brasileiro.

Um crescimento percentual na casa dos cinco milhões, em relação ao seu número de alunos, ajudou os acionistas da companhia a obter bons índices de lucratividade no mercado de ações da BM\&FBovespa, quando nos anos de 2013 e 2014, a Kroton liderou a lucratividade entre todas as empresas listadas na bolsa de valores. As estratégias de gestão corporativa da Estácio foram menos agressivas do que as de suas principais concorrentes, no mercado do ensino superior privado brasileiro. No entanto, depois da aquisição de uma grande $\mathbb{E S}$, em 2013, e com os novos investimentos em infraestrutura e expansão, no ano seguinte, as matrículas na companhia ultrapassaram a casa dos 300 mil, no primeiro ano, e 400 mil, no segundo.

Ainda em 2014, as matrículas da Kroton corresponderam a mais do que o dobro da sua principal concorrente, a Estácio. E foi no ensino a distância que a companhia deu seu maior salto, com a aquisição de grandes IES na modalidade, até a incorporação com a Anhanguera. Dentro dos fatores para as novas estratégias de gestão corporativa, não só da Kroton, mas inclusive das grandes IES do setor privado, de capital aberto ou fechado, mais uma vez, chama-se a atenção para a parceria com os Fundos de Equidade Privada, que injetaram elevadas somas de recursos nas companhias, ao comprar grande número de ações de algumas delas, no intuito de sua valorização em curto prazo.

Além das aquisições e fusões; da participação dos Fundos de Equidade Privada na gestão corporativa das companhias de ensino superior de capital aberto; da contratação de Executivos especializados no mercado financeiro; comentou-se sobre os currículos padronizados e a redução no número de funcionários (principalmente depois das aquisições), como estratégias para reduzir seu custo dos serviços prestados. 0 impacto pôde ser visto no crescimento do lucro bruto e lucro líquido, por exemplo, da Kroton, que por sua vez, aumentou os valores dos dividendos anuais para os acionistas. 
Os modelos educacionais padronizados das grandes companhias de capital aberto, como foi o caso da Anhanguera, Estácio e Kroton, com as novas estratégias de gestão corporativa, têm melhorado seus índices diante das avaliações determinadas pelo MEC, sobretudo depois da aquisição de IES com conceitos insatisfatórios que, ao incorporar o modelo de gestão de uma delas, melhora suas avaliações diante da instituição pública.

Se a receita bruta da Kroton quase dobrou depois da incorporação com a Anhanguera, apontou-se como o FlES teve participação importante nesse crescimento. Mais de $60 \%$ da base de alunos matriculados na graduação presencial da companhia, em 2014, contavam com o financiamento desse fundo; na Estácio, chegou a quase 40,0\%. Os $R \$ 2,3$ bilhões do FIES e PROUNI na receita bruta da Kroton, em 2014, representaram quase a metade dos $R \$ 4,7$ bilhões arrecadados pela companhia.

Por esse impacto dos recursos financeiros públicos nas contas das maiores IES do setor privado, em especial nas de capital aberto, pode-se observar como o preço das ações chegaram a oscilar, na bolsa de valores, quando das mudanças anunciadas no final de 2014, e adotadas em 2015, com relação aos novos financiamentos. Após dois anos de liderança na bolsa de valores, as ações da Kroton tiveram um período de desvalorização, assim que foram anunciadas as possibilidades de mudanças no FES. Outro produto que passou a ser oferecido pela Kroton e Estácio foi o PRONATEC, nos anos de 2013 e 2014 , totalmente financiamento pelo Fundo Público.

Mesmo com as críticas, ou opiniões favoráveis ao processo de financeirização do capital no ensino superior privado brasileiro, o fato é que a rentabilidade das ações na bolsa de valores, das companhias de capital aberto, principalmente da Kroton, constituiu-se como boa opção de investimento, no período observado, para olchess pequenos, médios e grandes acionistas. 0 acompanhamento de suas estratégias de gestão corporativa, nos próximos anos, permitirá detectar a continuidade, ruptura ou criação de novas alternativas para a condução dos seus negócios.

\section{REFERÊNCIAS}

ALONSO, 0. Saiba o que são private equity, venture capital e capital semente. Economia iG, 10 set. 2010. Disponivel em: http://economia.ig.com.br/mercados. Acesso em: 16 maio 2013.

AVILA, S. F. O. Mercantilização do ensino superior: as consequências das mudanças produtivas para os docentes de ensino superior. 2010. Tese (Curso de Pós-Graduação em Políticas Públicas e Formação Humana) - Universidade do Estado do Rio de Janeiro, Rio de Janeiro, 2010.

BALL, S. J. Performatividade, privatização e o pós-Estado de bem-estar. Educ. Soc., v. 25, n. 89, p. 1105-1126, set./dez. 2004. D0l: https://dx.doi.org/10.1590/S0101-73302004000400002. 
BARROS, B. T. de (org.). Fusões, aquisições e parceria. São Paulo: Atlas, 2001.

BENNETT, D. L.; LUCCHESI, A. R.; VEDDER, R. K. For-Profit Higher Education: Growth, Innovation and Regulation. Center for College Affordability and Productivity, p. 1-60, 2010. Disponivel em: http://www. centerforcollegeaffordability.org/. Acesso em: 11 abr. 2013.

BONVENTTI, R. C. Avanço verde-amarelo. Ensino Superior, São Paulo, n. 119, ago. 2008. Disponível em: http://revistaensinosuperior.uol.com.br/textos.asp? Acesso em: 15 out. 2009.

BRASIL. Instrução n. 391, de 16 de julho de 2003. Dispõe sobre a constituição, o funcionamento e a administração dos Fundos de Investimento em Participações. Comissão de Valores Mobiliários. São Paulo: CVM, 2003. Disponível em: http://www.cvm.gov.br/. Acesso em: 26 maio 2014.

BRASIL. Lei n. 6.385, de 7 de dezembro de 1976. Dispõe sobre o mercado de valores mobiliários e cria a Comissão de Valores Mobilírios. Diário Oficial da União, Brasilia, DF, 8 dez. 1976a.

BRASIL. Lei n. 6.404, de 15 de dezembro de 1976. Dispõe sobre a Sociedade por Ações. Diário Oficial da União, Brasília, DF, 16 dez. $1976 \mathrm{~b}$.

BRASIL. Projeto de Lei n. 7.200, de 12 de junho de 2006. Estabelece normas gerais da educação superior, regula a educação superior no sistema federal de ensino, altera as Leis nos 9.394, de 20 de dezembro de 1996; 8.958, de 20 de dezembro de 1994; 9.504, de 30 de setembro de 1997; 9.532, de 10 de dezembro de 1997; 9.870, de 23 de novembro de 1999; e dá outras providências. Diário Oficial da União, Brasilia, DF, 13 jun. 2006.

BURGARELLI, R. Explosão e implosão do Fies: como o ensino superior privado virou o centro dos gastos com educação do governo federal. In: MARINGONI, G. 0 negócio da educação: a aventura das universidades privadas na terra do capitalismo sem risco. São Paulo: Olho D'Água/FEPESP, 2017. p. 37-54.

CAMARGOS, M. A.; BARBOSA, F. V. Eficiência informacional do mercado de capitais brasileiro pós-Plano Real: um estudo de eventos dos anúncios de fusões e aquisições. R. Adm., v. 41, n. 1, p. 43-58, jan./ mar. 2006. Disponivel em: www.rausp.usp.br/download.asp?file=V4101043.pdf. Acesso em: 7 fev. 2013.

CARVALHO, C. H. A. A política pública para a educação superior no Brasil (1995-2008): ruptura e/ou continuidade? 2011. Tese (Curso de Pós-Graduação em Ciências Econômicas) - Universidade Estadual de Campinas, Campinas, 2011.

CARVALHO, C. H. A. A mercantilização da educação superior brasileira e as estratégias de mercado das instituições lucrativas. In: REUNIÃ̃ ANUAL DA ANPED, 35., 2012, Porto de Galinhas. Anais [...] Porto de Galinhas, 2012. p. 1-15. Disponível em: www.anped11.uerj.br/35/GT11-2301_int.pdf. Acesso em: 7 abr. 2013.

CHAVES, V. L. J. Expansão da privatização/mercantilização do ensino superior brasileiro: a formação dos oligopólios. Educação \& Sociedade, v. 31, n. 111, p. 481-500, abr./jun. 2010. 
CHESNAIS, F. A mundialização do capital. Tradução: S. F. Foá. São Paulo: Xamã, 1996.

CHESNAIS, F. 0 capital portador de juros: acumulação, internacionalização, efeitos econômicos e políticos. In: CHESNAIS, F. (org.). A finança mundializada. Tradução: Rosa Maria Marque e Paulo Nakatani. São Paulo: Boitempo, 2005. p. 35-67.

CMCONSULTORIA. Fusões e aquisições no ensino superior: panorama 2007-2014. [S. L.: s. n.], 2014. Disponível em: www.cmconsultoria.com.br. Acesso em: 16 maio 2014.

COSTA, F. L. O. Financeirização do capital no ensino superior privado com fins lucrativos no Brasil (2007-2012). 2016. Tese (Doutorado em Educação) - Universidade de São Paulo, São Paulo, 2016.

CUTRIM, R. S.; LÉDA, D. B. A financeirização do ensino superior privado e suas repercussões na dinâmica prazer e sofrimento do trabalho docente. In: SEMINÁRIO NACIONAL UNIVERSITAS/BR, 24., 2016. Anais [...] maio 2016. p. 1-16. Disponivel em: http://www.ppe.uem.br. Acesso em: 2 jun. 2017.

ESTÁCIO. Relatório Anual de 2013. [S. l.: s. n.], 2014. Disponível em: http://www.estacioparticipacoes.com. $\mathrm{br} / \mathrm{ri} /$. Acesso: 12 jun. 2017.

ESTÁCIO. Relatório Anual de 2014. [S. l.: s. n.], 2015. Disponivel em: http://www.estacioparticipacoes.com. $\mathrm{br} / \mathrm{ri} /$. Acesso: 12 jun. 2017.

GHIRARDI, J. G.; KLAFKE, G. F. Crescimento dos grupos educacionais de capital aberto (2010-2014). In: MARINGONI, G. 0 negócio da educação: a aventura das universidades privadas na terra do capitalismo sem risco. São Paulo: Olho D’água, 2017. p. 55-74.

GRAMANI, M. C. N. A influência da qualidade na atratividade de instituições de ensino superior com capital aberto. Ensaio: aval. Pol. Públ. Educ., v. 16, n. 60, p. 437-454, jul./set. 2008.

GUILHERME, P.; GLENIA, F. Faturamento de faculdades privadas cresce $30 \%$ em 2 anos, estima estudo. iG, 2013. Disponível em: http://gl.globo.com. Acesso: 16 maio 2014.

HESSEL, C. G.; MARREY, F. Investindo em educação. Capital Aberto, ano 5, n. 49, p. 52-56, set. 2007. Disponivel em: http://www.capitalaberto.com.br. Acesso em: 20 set. 2009.

KROTON. Relatório Anual de 2013. [S. L.: s. n., 2014. Disponível em: http://www.kroton.com.br/ri/. Acesso: 12 jun. 2017.

KROTON. Relatório Anual de 2014. [S. l.: s. n.], 2015. Disponível em: http://www.kroton.com.br/ri/. Acesso: 12 jun. 2017.

MALVESSI, 0. Análise econômico-financeira de empresas do setor de educação: período anual (20112015). In: MARINGONI, G. 0 negócio da educação: a aventura das universidades privadas na terra do capitalismo sem risco. São Paulo: Olho D’Água/FEPESP, 2017. p. 75-104. 
NAPOLITANO, C. Os tortuosos caminhos de uma mina de dinheiro. In: MARINGONI, G. 0 negócio da educação: a aventura das universidades privadas na terra do capitalismo sem risco. São Paulo: Otho D’Água/FEPESP, 2017. p. 11-26.

OLIVEIRA, R. P. A financeirização da economia e suas consequências para a educação superior no Brasil. In: MARINGONI, G. 0 negócio da educação: a aventura das universidades privadas na terra do capitalismo sem risco. São Paulo: Olho D’Água/FEPESP, 2017. p. 27-35.

OLIVEIRA, R. P. A transformação da educação em mercadoria no Brasil. Educação \& Sociedade, v. 30, n. 108, p. 739-760, out. 2009. D0l: https://dx.doi.org/10.1590/S0101-73302009000300006.

POLIZEL, C.; STEINBERG, H. Governança corporativa na educação superior: casos práticos de instituições privadas (com e sem fins lucrativos). São Paulo: Saraiva, 2013.

SARFATI, G.; SHWARTZBAUM, A. Sinergias nas fusões e aquisições do setor de educação superior no Brasil. RPCA, v. 7, n. 4, p. 1-23, out./dez. 2013. Disponivel em: www.uff.br/pae/index.php/pca/article/ viewFile/317/225. Acesso em: 11 maio 2014.

SGUISSARDI, V. Estudo Diagnóstico da Política de Expansão da (e Acesso à) Educação Superior no Brasil - 2002-2012. Brasília, DF: [s. n., 2014.

SOUSA, D. Anhanguera vai frear aquisições no ano que vem. 0 Estado de São Paulo, 14 dez. 2012. Disponivel em: www.cmconsultoria.com.br. Acesso em: 10 abr. 2014.

VALE, A. A. As faculdades privadas não fazem pesquisa porque não querem jogar dinheiro fora": a trajetória da Estácio de Sá da filantropia ao mercado financeiro. 2011. Tese (Curso de Pós-Graduação em Políticas Públicas e Formação Humana) - Universidade do Estado do Rio de Janeiro, Rio de Janeiro, 2011.

Endereço para correspondência: Cidade Universitária de Dourados, Rodovia Itahum, Km 12, s/n, Jardim Aeroporto, Dourados, Mato Grosso do Sul; costalofabio@gmail.com 